Article

\title{
Investigation of Comfort Temperature and Occupant Behavior in Japanese Houses during the Hot and Humid Season
}

\author{
Hom B. Rijal \\ Department of Restoration Ecology and Built Environment, Faculty of Environmental Studies, \\ Tokyo City University, 3-3-1 Ushikubo-nishi, Tsuzuki-ku, Yokohama 224-8551, Japan; \\ E-Mail: rijal@tcu.ac.jp; Tel.: +81-45-910-2616; Fax: +81-45-910-2605
}

Received: 29 April 2014; in revised form: 26 June 2014 / Accepted: 19 August 2014 /

Published: 26 August 2014

\begin{abstract}
In order to clarify the comfort temperature and to investigate the behavioral adaptation in Japanese houses, we have conducted a thermal comfort survey and occupant behavior survey in 30 living rooms during the hot and humid season in the Kanto region of Japan. We collected 3991 votes from 52 subjects. The comfort temperature was predicted by Griffiths' method. They are analyzed according to humidity levels and compared with the adaptive model. The logistic regression analysis was conducted in order to understand occupant behavior. The mean comfort temperature in naturally ventilated mode is $27.6{ }^{\circ} \mathrm{C}$ which is within the acceptable zone of the adaptive model. The comfort temperature is related with skin moisture sensation. The results showed that the residents adapt to the hot and humid environments by increasing the air movement using behavioral adaptation such as window opening and fan use.
\end{abstract}

Keywords: houses; thermal comfort survey; Probit analysis; Griffiths method; humidity; comfort temperature; adaptive model; occupant behavior; window opening; fan use

\section{Introduction}

The basic survival needs for human beings are food, clothing and housing. People tend to choose the most comfortable and favorable of these items available during their life. People also want to buy and live in a comfortable home, which normally represents their most significant expenditure in their lifetime. Thus, it is highly important to build a comfortable home to fulfill this desire of the average person. 
It is thought that thermal comfort is one of the most important factors in creating the most comfortable homes. By investigating and establishing the comfort temperature of the residents, this can be used as the customary temperature of the house to minimize excessive energy use and save the overall energy costs of the household. There have already been a number of research projects about the comfort temperature of houses in Japan [1-5], Nepal [6], Pakistan [7,8] and UK [9]. The Japanese summer is especially hot and humid, and the Japanese government recommends the indoor temperature setting of $28{ }^{\circ} \mathrm{C}$ without supporting evidence from any field survey. Thus, we need to investigate the comfort temperatures and effect of humidity on the environments and occupants concerned.

Recently, ASHRAE [10] and CEN [11] have proposed the adaptive model for naturally ventilated and free running building design. The adaptive models are based on a thermal comfort survey, mainly in the European and American offices, and Japanese data is not included in them. The occupants' behavior in the office and at home is different, and thus the exiting adaptive models may not be applicable to residences which need to be compared using the Japanese data.

In hot and humid conditions, air movement is the important factor in determining the indoor comfort temperature [12]. Behavioral adaptation such as window opening and fan use might be useful to increase the air movement for adaptive thermal comfort. However, how people behaviorally adapt to the hot and humid season is not yet fully understood.

In order to clarify the comfort temperature and investigate the behavioral adaptation in Japanese houses, we have conducted our thermal comfort survey and occupant behavior survey in 30 living rooms during the hot and humid season in the Kanto region of Japan.

\section{Field Investigation}

The indoor air temperature, the globe temperature and the relative humidity were measured in the living room, avoiding direct sunlight, at ten minute intervals using a data logger (Figure 1, Table 1). Outdoor air temperature and relative humidity were obtained from the nearest meteorological station. The number of subjects comprised 25 males and 27 females. The thermal comfort survey was conducted from 25 July to 17 September 2012 (hot and humid season) several times a day using a 7 point thermal sensation scale and a 5 point thermal preference scale (Figure 2). Occupant behavior in the living room was recorded in binary form several times a day $(0=$ window closed or cooling off or fan off, 1 = window open or cooling on or fan on). We collected 3991 votes. These data were analyzed by the SPSS version 19 .

Figure 1. Measurement of indoor air temperature, globe temperature and relative humidity.

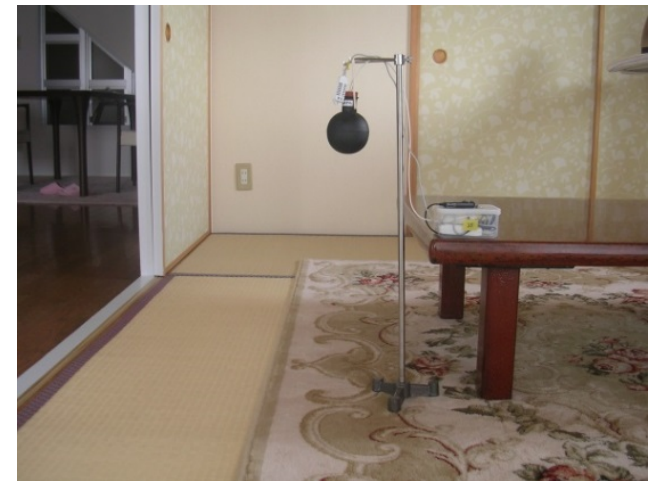


Table 1. Details of the instruments used for the environmental measurement.

\begin{tabular}{cccc}
\hline Parameter Measured & Trade Name & Range & Accuracy \\
\hline \multirow{2}{*}{ Air temperature, Humidity } & TR-74Ui & 0 to $55^{\circ} \mathrm{C}, 10$ to $95 \% \mathrm{RH}$ & $\pm 0.5{ }^{\circ} \mathrm{C}, \pm 5 \%$ \\
& RTR-53A & 0 to $55{ }^{\circ} \mathrm{C}, 10$ to $95 \% \mathrm{RH}$ & $\pm 0.3{ }^{\circ} \mathrm{C}, \pm 5 \%$ \\
\hline \multirow{2}{*}{ Globe temperature } & Tr-52i & -60 to $155^{\circ} \mathrm{C}$ & $\pm 0.3{ }^{\circ} \mathrm{C}$ \\
& SIBATA $080340-75$ & Black painted $75 \mathrm{~mm}$ diameter globe \\
\hline
\end{tabular}

Figure 2. (a) ASHRAE scale; (b) The Society of Heating, Air-Conditioning and Sanitary Engineers of Japan (SHASE) scale; (c) Thermal preference scale; (d) Skin moisture sensation.

(a) ASHRAE scale: How do you feel air temperature at this time?

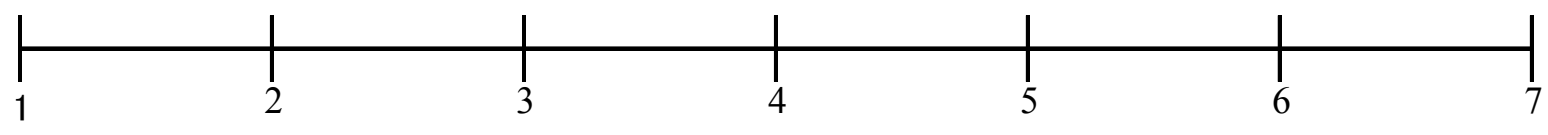

Cold Cool Slightly cool Neutral Slightly warm Warm Hot

(b) SHASE scale: How do you feel air temperature at this time?

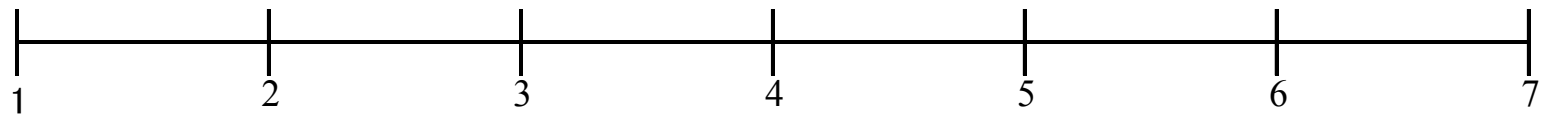

$\begin{array}{lllll}\text { Very cold } & \text { Cold } & \text { Slightly cold Neutral } & \text { Slightly hot } & \text { Hot }\end{array}$ Neither cold nor hot

(c) Thermal preference scale: How do you prefer air temperature at this time?

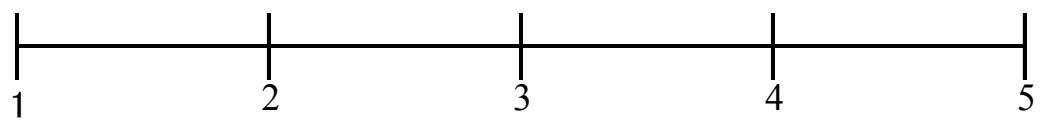

Much warmer Slightly warmer No change Slightly cooler Much cooler

(d) Skin moisture feeling: How do you feel skin moisture at this time?

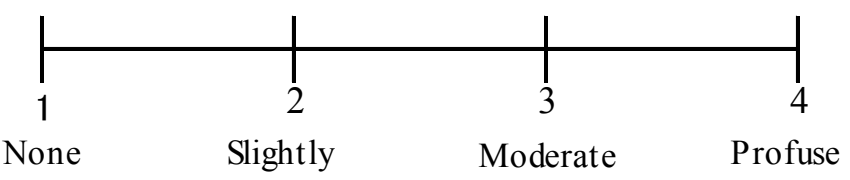

Even though the ASHRAE scale is frequently used to evaluate the thermal sensation, the words "warm" or "cool" imply comfort in Japanese, and thus the SHASE (The Society of Heating, Air-Conditioning and Sanitary Engineers of Japan) scale is also used to evaluate the thermal sensation. To avoid the possible misunderstanding of "neutral" in the thermal sensation scale, it is explained as "neutral (neither cold nor hot)" (SHASE scale) or "neutral (neither cool nor warm)" (ASHRAE scale). It is also said that the optimum temperature occurs on the cooler side in summer and on the warmer side in winter $[1,13]$. 


\section{Results and Discussion}

\subsection{The Modes}

The data were divided into two groups: the NV mode (naturally ventilated) and AC mode (cooling by air conditioning). First, we have determined the AC mode based on actual cooling used. Then, all the other data were classified as being in the NV mode. So, strictly speaking, the NV mode is the "free running" mode where the cooling is not being used to control the indoor environment [14].

\subsection{Distribution of Temperature and Humidity}

Figure 3 shows the monthly mean temperature and relative humidity in NV and AC modes. Table 2 shows the correlation coefficient in NV and AC modes.

The monthly mean indoor and globe temperature is very similar in NV and AC mode, and thus the correlation coefficient is also high in both modes. In NV mode, indoor temperatures are higher than the outdoor air temperature. However, in AC mode, the indoor temperatures are lower than the outdoor air temperature, except in September. The Japanese government recommends the indoor temperature settings of $28^{\circ} \mathrm{C}$ in summer. The results showed that the mean indoor temperature setting in $\mathrm{AC}$ mode was similar to the recommendation.

The mean indoor relative humidity is lower than the outdoor relative humidity (Figure $3 \mathrm{~b}$ ). Due to the mechanical cooling, the mean indoor relative humidity or correlation coefficient of the AC mode is lower than the NV mode. The results showed that the relative humidity is slightly higher than the standard: $60 \%$.

Figure 3. Monthly mean temperature (a) and relative humidity (b) in naturally ventilated $(\mathrm{NV})$ and cooling by air conditioning $(\mathrm{AC})$ modes during voting.

(a) Temperature

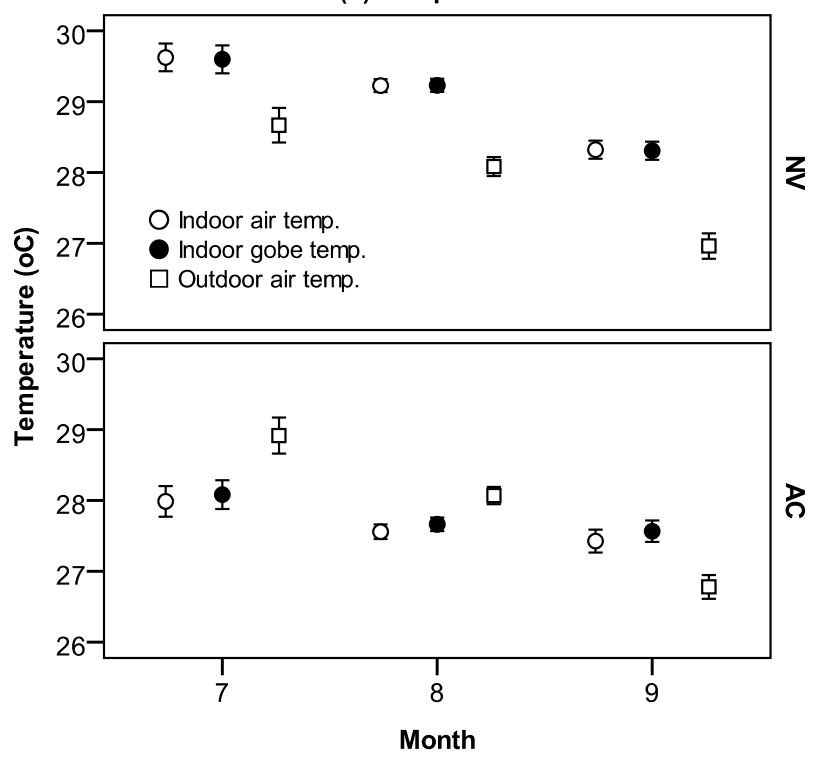

(b) Relitive humidity

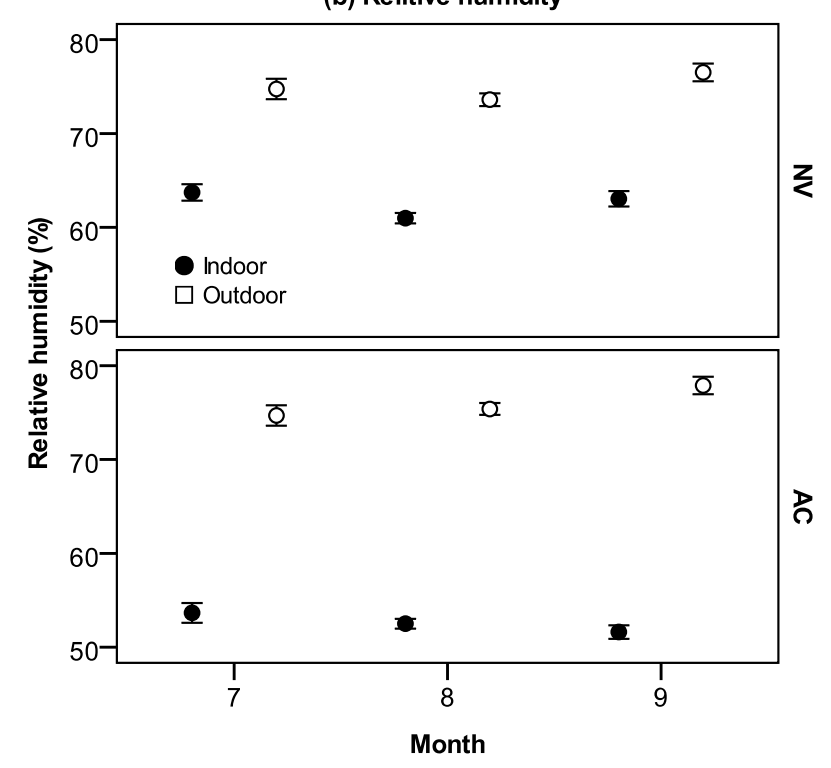


Table 2. Correlation coefficient in NV and AC modes.

\begin{tabular}{cccccc}
\hline Mode & Items & $\boldsymbol{T}_{\mathbf{i}}: \boldsymbol{T}_{\mathbf{0}}$ & $\boldsymbol{T}_{\mathrm{g}}: \boldsymbol{T}_{\mathbf{0}}$ & $\boldsymbol{T}_{\boldsymbol{i}}: \boldsymbol{T}_{\mathrm{g}}$ & $\boldsymbol{R H}_{\boldsymbol{i}}: \boldsymbol{R} \boldsymbol{H}_{\mathbf{0}}$ \\
\hline \multirow{2}{*}{$\mathrm{NV}$} & $r$ & 0.57 & 0.57 & 0.98 & 0.50 \\
& $N$ & 1860 & 1915 & 1860 & 1860 \\
\hline \multirow{2}{*}{ AC } & $r$ & 0.22 & 0.20 & 0.89 & 0.07 \\
& $N$ & 1805 & 2076 & 1805 & 1805 \\
\hline
\end{tabular}

$T_{i}$ : Indoor air temperature $\left({ }^{\circ} \mathrm{C}\right) ; T_{\mathrm{g}}$ : Indoor globe temperature $\left({ }^{\circ} \mathrm{C}\right) ; T_{\mathrm{o}}$ : Outdoor air temperature $\left({ }^{\circ} \mathrm{C}\right)$; $R H_{i}$ : Indoor relative humidity (\%); $R H_{0}$ : Outdoor relative humidity (\%); $r$ : Correlation coefficient; $N$ : Number of sample; Correlation coefficient is significant at the 0.01 level (2-tailed).

\subsection{Distribution of Thermal Sensation}

Table 3 shows the correlation coefficient of the thermal sensation and thermal preference or temperatures. The correlation coefficient of the SHASE scale and thermal preference is higher than the ASHRAE scale and thermal preference. The SHASE scale is better correlated with the indoor air temperature and globe temperature. Thus, we have used the SHASE scale for further analysis.

Mean thermal sensation vote was 4.7 in NV mode, 4.3 in AC mode. Even though residents used the cooling, they sometimes felt "hot". The proportion of people voting in the thermal comfort zone (votes 3, 4 or 5) in the NV and AC modes is $84 \%$ and $97 \%$ (Table 4).

It can be said that residents were generally satisfied in the thermal environment of their houses. This may be due to the thermal adaptation of the residents to the local climate and culture.

Table 3. Correlation coefficient with ASHRAE and SHASE scales.

\begin{tabular}{cccccccc}
\hline \multirow{2}{*}{ Mode } & \multirow{2}{*}{ Items } & \multicolumn{3}{c}{ ASHRAE } & \multicolumn{3}{c}{ SHASE } \\
\cline { 3 - 8 } & & $\mathbf{T P}$ & $\boldsymbol{T}_{\boldsymbol{i}}$ & $\boldsymbol{T}_{\mathbf{g}}$ & $\mathbf{T P}$ & $\boldsymbol{T}_{\boldsymbol{i}}$ & $\boldsymbol{T}_{\mathbf{g}}$ \\
\hline \multirow{2}{*}{ NV } & $r$ & 0.73 & 0.36 & 0.36 & 0.81 & 0.38 & 0.37 \\
& $N$ & 1,915 & 1860 & 1915 & 1915 & 1860 & 1915 \\
\hline \multirow{2}{*}{ AC } & $r$ & 0.77 & 0.30 & 0.28 & 0.86 & 0.35 & 0.32 \\
& $N$ & 2076 & 1805 & 2076 & 2076 & 1805 & 2076 \\
\hline
\end{tabular}

TP: Thermal preference; $T_{i}$ : Indoor air temperature $\left({ }^{\circ} \mathrm{C}\right) ; T_{\mathrm{g}}$ : Globe temperature $\left({ }^{\circ} \mathrm{C}\right) ; p<0.001 ; p$ : Significant level; $r$ : Correlation coefficient; $N$ : Number of sample.

Table 4. Percentage of thermal sensation in NV and AC modes.

\begin{tabular}{|c|c|c|c|c|c|c|c|c|c|}
\hline \multirow{2}{*}{ Mode } & \multirow{2}{*}{ Items } & \multicolumn{7}{|c|}{ Thermal Sensation } & \multirow{2}{*}{ Total } \\
\hline & & 1 & 2 & 3 & 4 & 5 & 6 & 7 & \\
\hline \multirow{2}{*}{ NV } & $N$ & 1 & - & 24 & 904 & 685 & 253 & 48 & 1915 \\
\hline & $P(\%)$ & 0.1 & - & 1.3 & 47.2 & 35.8 & 13.2 & 2.5 & 100 \\
\hline \multirow{2}{*}{$\mathrm{AC}$} & $N$ & 2 & 5 & 152 & 1284 & 569 & 58 & 6 & 2076 \\
\hline & $P(\%)$ & 0.1 & 0.2 & 7.3 & 61.8 & 27.4 & 2.8 & 0.3 & 100 \\
\hline
\end{tabular}

$N$ : Number of sample; $P$ : Percentage. 


\subsection{Thermal Comfort Zone}

To clarify the thermal comfort zone, the Probit regression analysis [15] is conducted for the thermal sensation votes (TSV) (SHASE scale) categories and temperatures for NV and AC modes. The analysis method is Ordinal regression using Probit as the link function and the temperature as the covariate.

The results of the Probit analysis is shown in Table 5. The "mean" temperature is calculated by dividing the constant by regression coefficient. For example, the mean temperature of the first equation will be $4.790 / 0.289=16.6^{\circ} \mathrm{C}$ (Table 5). The inverse of the Probit regression is the standard deviation of the cumulative Normal distribution. For example, the standard deviation of air temperature of the NV mode will be $1 / 0.289=3.460{ }^{\circ} \mathrm{C}$ (Table 5). These calculations are fully given in the Table 5 . Transforming the Probits using the following function into proportions gives the curve of Figure $4 \mathrm{a}-\mathrm{d}$. The vertical axis is the proportion of votes.

$$
\text { Probability }=\text { CDF.NORMAL (quant, mean, S.D.) }
$$

where the "quant" is the indoor air temperature $\left({ }^{\circ} \mathrm{C}\right)$ or globe temperature $\left({ }^{\circ} \mathrm{C}\right)$, the "mean" and "S.D." are given in the Table 5.

The highest line is for category 1 (very cold) and so on successively. Thus, it can be seen that the temperature for thermal neutrality (a probability of 0.5 ) is around $26{ }^{\circ} \mathrm{C}$ for the $\mathrm{AC}$ mode.

Reckoning the three central categories as representing thermal comfort, and transforming the Probits into proportions gives the bell-curve of Figure 4e,f. The result is remarkable in two respects. The proportion of people comfortable at the optimum is very high for AC mode, only just less that $100 \%$, and the range over which $80 \%$ are comfortable is wide-from around 23 to $30{ }^{\circ} \mathrm{C}$ in NV mode. This is presumably because people in their own homes are free to clothe themselves according to the room temperature, without the constraints that are apt to apply at the office.

Table 5. Results of the Probit analysis for NV and AC modes.

\begin{tabular}{ccccccc}
\hline \multirow{2}{*}{ Mode } & \multicolumn{2}{c}{ Indoor air temperature $\boldsymbol{T}_{\boldsymbol{i}}\left({ }^{\circ} \mathbf{C}\right)$} & \multicolumn{2}{c}{ Globe temperature $\boldsymbol{T}_{\mathbf{g}}\left({ }^{\circ} \mathbf{C}\right)$} \\
\cline { 2 - 8 } & Equation & Mean & S.D. & Equation & Mean & S.D. \\
\hline \multirow{4}{*}{ NV } & $P_{(\leq 1)}=0.289 T_{i}-4.790$ & 16.6 & & $P_{(\leq 1)}=0.285 T_{\mathrm{g}}-4.691$ & 16.5 & \\
& $P_{(\leq 2)}=0.289 T_{i}-5.919$ & 20.5 & & $P_{(\leq 2)}=0.285 T_{\mathrm{g}}-5.817$ & 20.4 & \\
& $P_{(\leq 4)}=0.289 T_{i}-8.292$ & 28.7 & 3.460 & $P_{(\leq 4)}=0.285 T_{\mathrm{g}}-8.238$ & 28.9 & 3.509 \\
& $P_{(\leq 5)}=0.289 T_{i}-9.461$ & 32.7 & & $P_{(\leq 5)}=0.285 T_{\mathrm{g}}-9.388$ & 32.9 & \\
& $P_{(\leq 6)}=0.289 T_{i}-10.506$ & 36.4 & & $P_{(\leq 6)}=0.285 T_{\mathrm{g}}-10.424$ & 36.6 & \\
\hline \multirow{4}{*}{$\mathrm{AC}$} & $P_{(\leq 1)}=0.260 T_{i}-3.861$ & 14.9 & & $P_{(\leq 1)}=0.250 T_{\mathrm{g}}-3.701$ & 14.8 & \\
& $P_{(\leq 2)}=0.260 T_{i}-4.150$ & 16.0 & & $P_{(\leq 2)}=0.250 T_{\mathrm{g}}-4.085$ & 16.3 & \\
& $P_{(\leq 3)}=0.260 T_{i}-5.655$ & 21.8 & 3.846 & $P_{(\leq 3)}=0.250 T_{\mathrm{g}}-5.410$ & 21.6 & \\
& $P_{(\leq 4)}=0.260 T_{i}-8.043$ & 30.9 & & $P_{(\leq 4)}=0.250 T_{\mathrm{g}}-7.506$ & 30.0 & 3.846 \\
& $P_{(\leq 5)}=0.260 T_{i}-9.210$ & 35.4 & & $P_{(\leq 5)}=0.250 T_{\mathrm{g}}-8.953$ & 35.8 & \\
& $P_{(\leq 6)}=0.260 T_{i}-10.118$ & 38.9 & & $P_{(\leq 6)}=0.250 T_{\mathrm{g}}-9.912$ & 39.6 & \\
\hline
\end{tabular}

$P_{(\leq 1)}$ is the Probit of proportion of the votes that are 1 and less, $P_{(\leq 2)}$ is the Probit of the proportion that are 2 and less, and so on, S.D.: Standard deviation of the cumulative Normal distribution. 
Figure 4. Proportion of thermal sensation vote (TSV) or comfortable (TSV 3, 4 or 5) for temperatures: (a) Proportion of $\mathrm{TSV}$ and indoor air temperature in NV mode; (b) Proportion of TSV and globe temperature in NV mode; (c) Proportion of TSV and indoor air temperature in AC mode; (d) Proportion of TSV and globe temperature in AC mode; (e) Proportion of comfortable and indoor air temperature; (f) Proportion of comfortable and globe temperature.

(a) NV

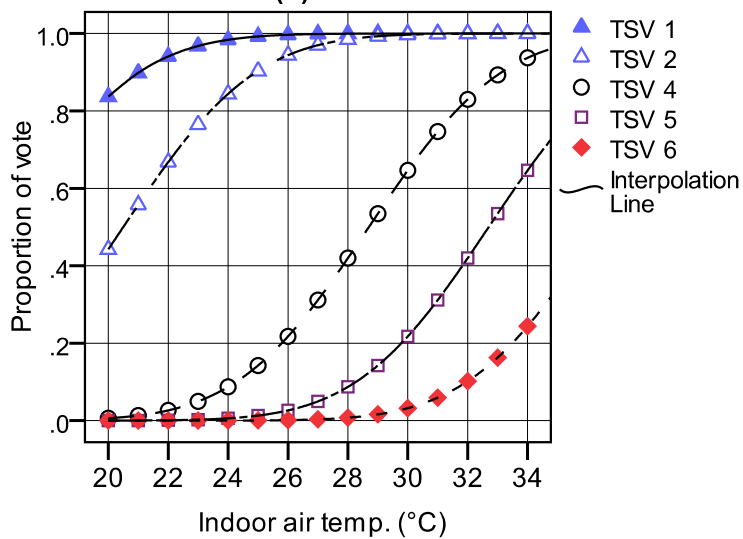

(c) AC

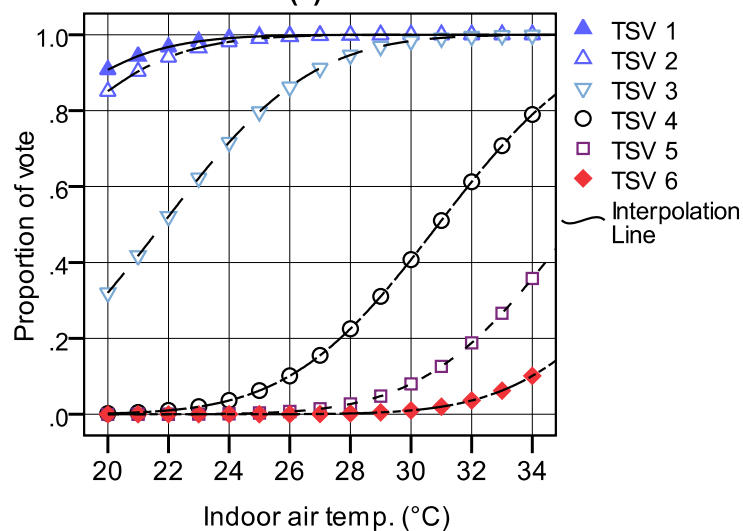

(e)

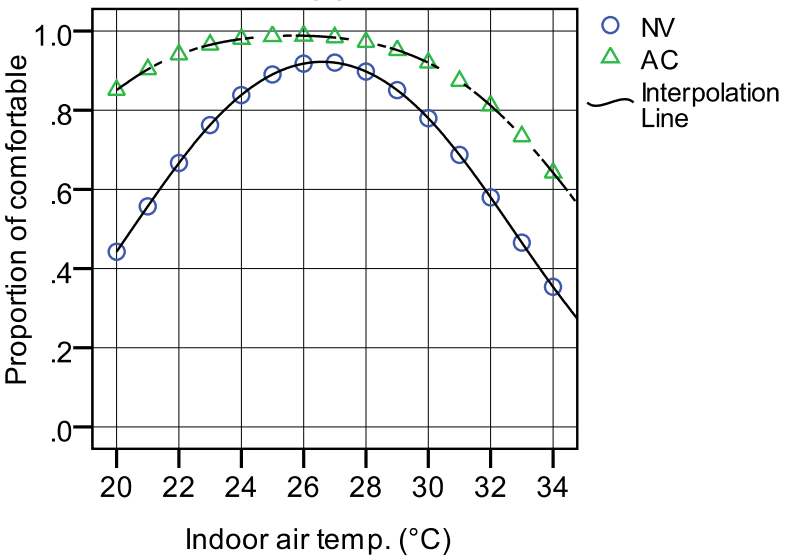

(b) NV

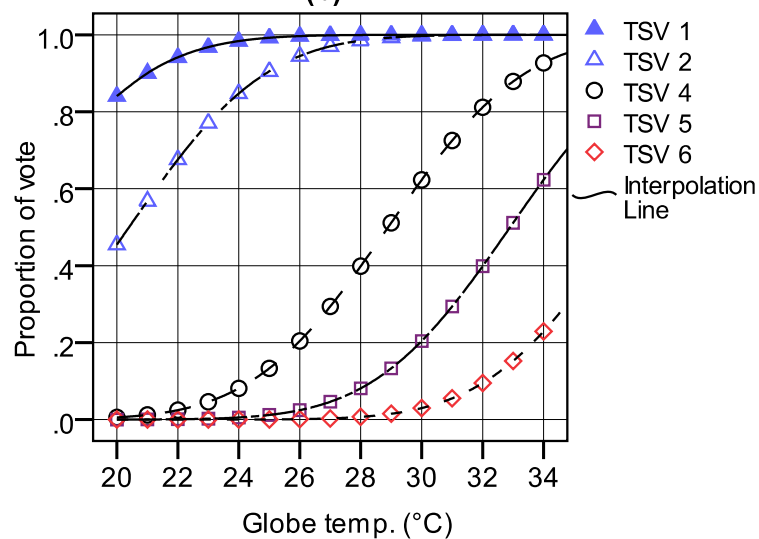

(d) AC

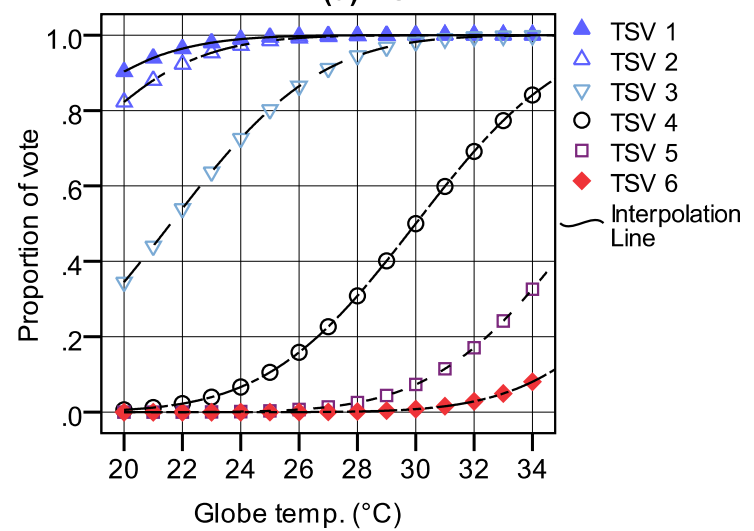

(f)

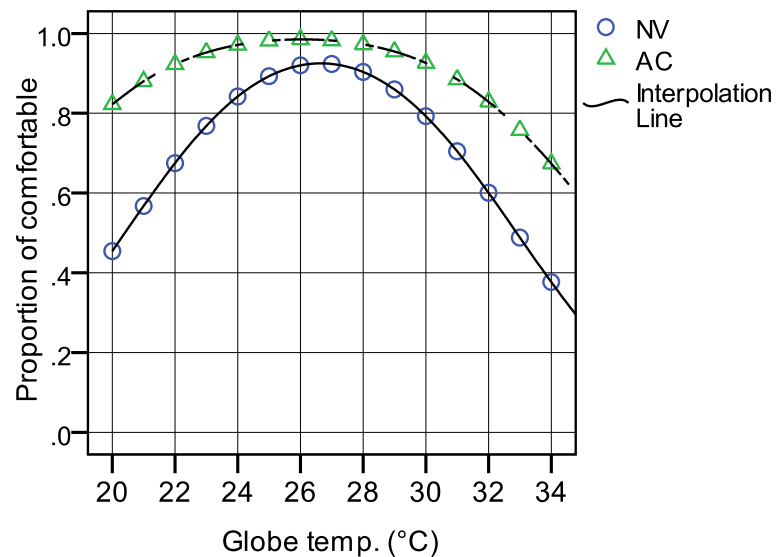

\subsection{Prediction of Comfort Temperature by Regression Method}

Regression analysis of the thermal sensation and indoor air temperature was conducted to predict the comfort temperature (Figure 5). The following regression equations are obtained for the thermal sensation $(C)$ and indoor air temperature $\left(T_{i},{ }^{\circ} \mathrm{C}\right)$ or globe temperature $\left(T_{\mathrm{g}},{ }^{\circ} \mathrm{C}\right)$. 
NV mode:

$$
\begin{aligned}
& C=0.192 T_{i}-0.872\left(n=1860, R^{2}=0.14, p<0.001\right) \\
& C=0.189 T_{\mathrm{g}}-0.809\left(n=1915, R^{2}=0.14, p<0.001\right)
\end{aligned}
$$

AC mode:

$$
\begin{aligned}
& C=0.125 T_{i}+0.705\left(n=1805, R^{2}=0.12, p<0.001\right) \\
& C=0.134 T_{\mathrm{g}}+0.523\left(n=2076, R^{2}=0.11, p<0.001\right)
\end{aligned}
$$

$n$ : Number of sample; $R^{2}$ : Coefficient of determination; $p$ : Significant level of regression coefficient.

The regression coefficient for the NV mode is higher than that of the AC. When the indoor or globe comfort temperature is predicted by substituting " 4 neutral" in the Equations (2) to (5), it would be $25.4{ }^{\circ} \mathrm{C}$ in the $\mathrm{NV}$ mode and $26.4{ }^{\circ} \mathrm{C}$ or $25.9^{\circ} \mathrm{C}$ in the $\mathrm{AC}$ mode.

As shown in the figure, the comfort temperature is predicted around the few data points, and thus a linear model is not suitable to predict the comfort temperature. This might be due to the problem of applying the regression method in the presence of adaptive behavior, where it can be misleading when used to estimate the comfort temperature, as has been found in previous research $[5,6]$. So to avoid this problem the comfort temperature is estimated using the Griffiths method in the next section.

Figure 5. Relation between thermal sensation and the temperature: (a) Thermal sensation and indoor air temperature; (b) Thermal sensation and indoor globe temperature.

(a)

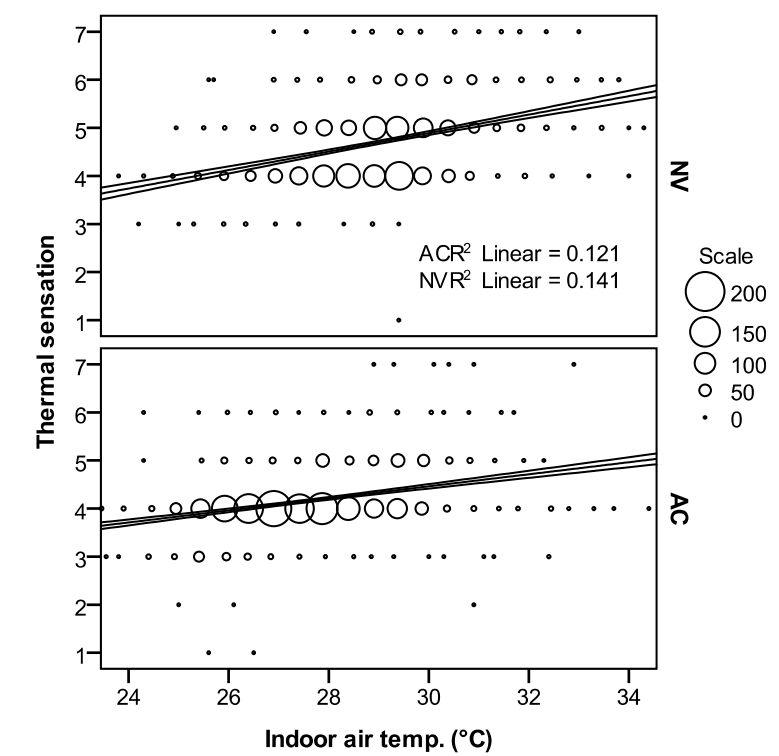

(b)

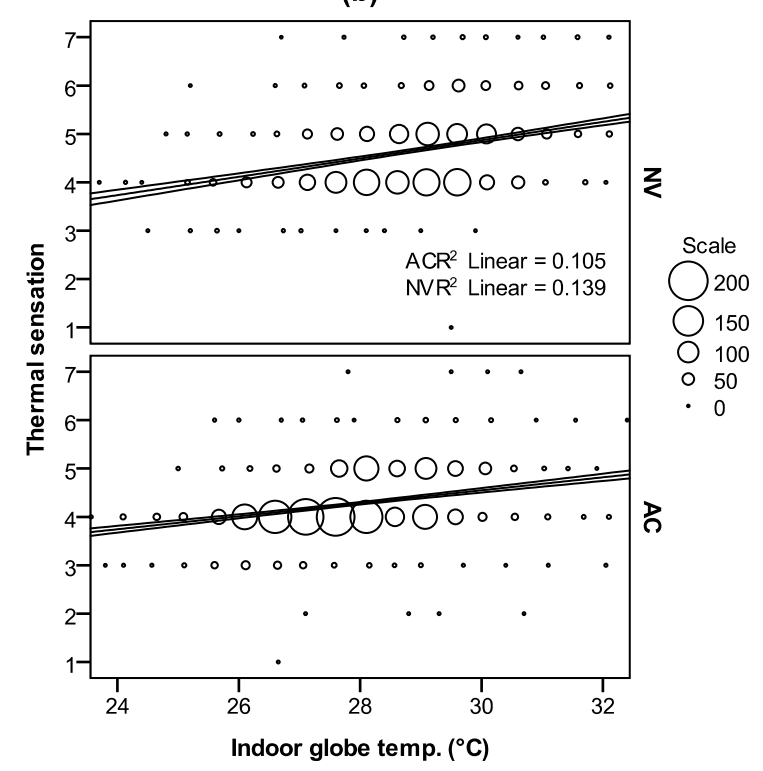

\subsection{Prediction of Comfort Temperature by Griffiths Method}

Griffiths [16] suggested a way in which the comfort temperature can be calculated from a small sample of data. Griffiths made the assumption that the increase in temperature for each scale point on the thermal sensation scale was effectively $3 \mathrm{~K}$ for a seven point scale [17]. This means that for each thermal sensation vote away from neutral, he subtracted or added $3 \mathrm{~K}$ from the actual temperature at the time to obtain the temperature that might be expected to result in neutrality [17]. The detail of the 
Griffiths method can be found in the various publications [7,17,18]. The comfort temperature is predicted by the Griffiths' method which is given below.

$$
T_{\mathrm{c}}=T+(4-C) / a
$$

where $T_{\mathrm{c}}$ is the comfort temperature by Griffiths' method $\left({ }^{\circ} \mathrm{C}\right), T$ is the indoor air temperature $\left({ }^{\circ} \mathrm{C}\right)$ or globe temperature $\left({ }^{\circ} \mathrm{C}\right)$ and $a$ is the regression coefficient.

In applying the Griffiths' method, Nicol et al. [7] and Humphreys et al. [19] used the constants $0.25,0.33$ and 0.50 for a 7 point thermal sensation scale. We have also investigated the comfort temperature using these regression coefficients. The mean comfort temperature with each coefficient is not very different (Table 6), so it matters little which coefficient is adopted. The comfort temperature calculated with the coefficient 0.50 is used for further analysis.

Table 6. Comfort temperature predicted by Griffiths' method.

\begin{tabular}{cccccccc}
\hline \multirow{2}{*}{ Mode } & \multirow{2}{*}{$\mathbf{R C}$} & \multicolumn{3}{c}{$\boldsymbol{T}_{\mathbf{c i}}\left({ }^{\circ} \mathbf{C}\right)$} & \multicolumn{3}{c}{$\boldsymbol{T}_{\mathbf{c g}}\left({ }^{\circ} \mathbf{C}\right)$} \\
\cline { 3 - 8 } & & $\boldsymbol{N}$ & Mean & S.D. & $\boldsymbol{N}$ & Mean & S.D. \\
\hline \multirow{3}{*}{ NV } & 0.25 & 1860 & 26.2 & 3.1 & 1915 & 26.3 & 3.0 \\
& 0.33 & 1860 & 26.9 & 2.4 & 1915 & 26.9 & 2.4 \\
& 0.50 & 1860 & 27.6 & 1.8 & 1915 & 27.6 & 1.8 \\
\hline \multirow{4}{*}{ AC } & 0.25 & 1805 & 26.9 & 2.5 & 2076 & 26.8 & 2.6 \\
& 0.33 & 1805 & 27.1 & 2.1 & 2076 & 27.0 & 2.1 \\
& 0.50 & 1805 & 27.3 & 1.8 & 2076 & 27.3 & 1.7 \\
\hline
\end{tabular}

RC: Regression coefficient; $T_{\text {ci }}$ : Comfort indoor temperature; $T_{\text {cg }}$ : Comfort globe temperature; $N$ : Number of sample; S.D.: Standard deviation.

The mean comfort air or globe temperature by the Griffiths' method is $27.6^{\circ} \mathrm{C}$ in $\mathrm{NV}$ mode and $27.3{ }^{\circ} \mathrm{C}$ in AC mode (Figure 6). Since the mean comfort temperature of the Griffiths' method is comparable to the indoor air and globe temperature when voting " 4 neutral" (Table 7). It is probable that the comfort temperature as estimated by the Griffiths' method is more appropriate.

Table 8 shows a comparison of the comfort temperature obtained in this study with existing research. The comfort temperature of the existing research is similar to this research.

Figure 6. Comfort temperature predicted by Griffiths method: (a) Comfort indoor air temperature; (b) Comfort globe temperature.

(a)

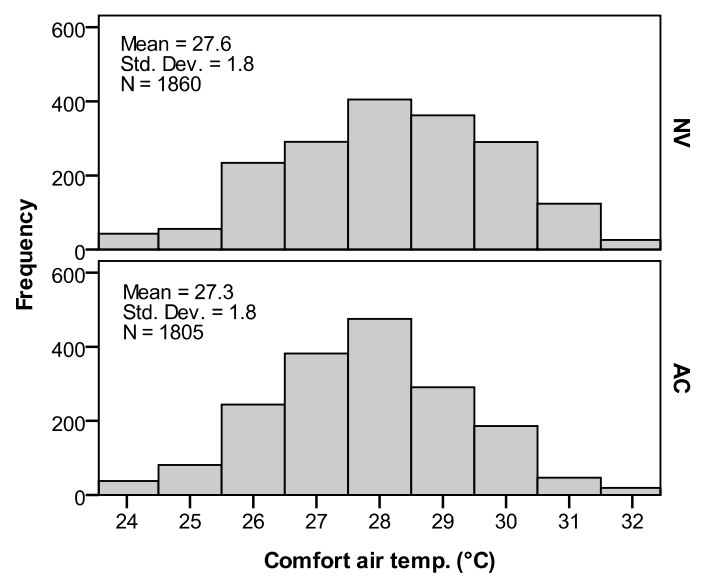

(b)

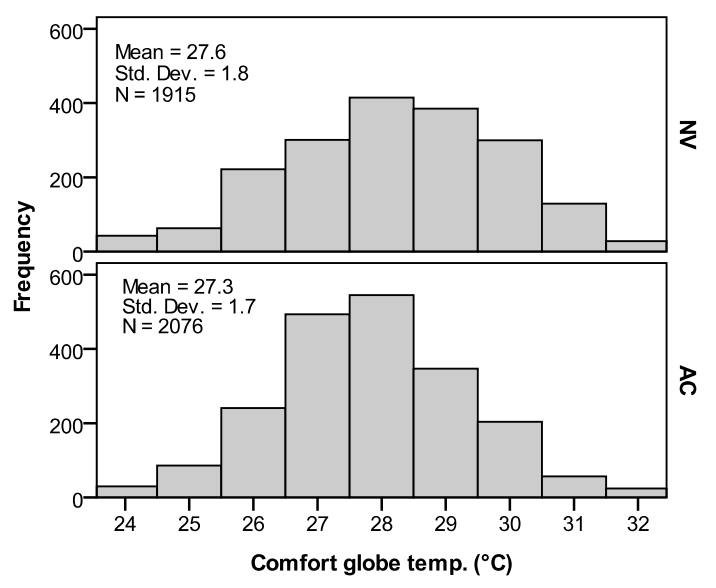


Table 7. Indoor air temperature and globe temperature when voting "4 neutral".

\begin{tabular}{ccccc}
\hline Mode & Items & $\boldsymbol{N}$ & Mean $\left({ }^{\circ} \mathbf{C}\right)$ & S.D. $\left({ }^{\circ} \mathbf{C}\right)$ \\
\hline \multirow{2}{*}{$\mathrm{NV}$} & $T_{i}$ & 851 & 28.5 & 1.5 \\
& $T_{\mathrm{g}}$ & 904 & 28.5 & 1.5 \\
\hline \multirow{2}{*}{$\mathrm{AC}$} & $T_{i}$ & 1264 & 27.4 & 1.7 \\
& $T_{\mathrm{g}}$ & 1284 & 27.6 & 1.6 \\
\hline
\end{tabular}

$T_{i}$ : Indoor air temperature; $T_{\mathrm{g}}$ : Indoor globe temperature; S.D.: Standard deviation.

Table 8. Comparison of comfort temperature in summer with existing research.

\begin{tabular}{ccc}
\hline Area & Reference & Comfort Temperature $\left({ }^{\circ} \mathbf{C}\right)$ \\
\hline Japan (Kanto) & This study (NV mode) & 27.6 \\
Japan (Gifu) & Rijal et al. $[5]$ & 26.1 \\
Japan (Kanto) & Katsuno et al. $[4]$ & 27.6 \\
Japan (Kanto) & Yoshimura et al. $[2]$ & 29 \\
Japan (Kanto) & Rijal and Yoshimura [3] & $27.2 *$ \\
Japan (Kansai) & Nakaya et al. $[1]$ & 27.6 \\
Nepal & Rijal et al. $[6]$ & $21.1-30.0$ \\
Pakistan & Nicol and Roaf [8] & $26.7-29.9$ \\
UK & Rijal and Stevenson [9] & 22.9 \\
\hline
\end{tabular}

*: Summer and autumn.

\subsection{Comfort Temperature and Humidity}

The humidity is one of the key issues in the hottest season. In a moist environment, people become uncomfortable with a smaller change in temperature than they do in a dry environment [12]. The comfort temperature is analyzed by relating it to the relative humidity, absolute humidity and skin moisture. The comfort temperatures were correlated with the indoor relative humidity and skin moisture sensation (Table 9). However, the correlation effect of the comfort temperature and relative humidity might have simply been arrived at from the correlation between air temperature and relative humidity. To investigate the effect of humidity on the comfort temperature, the multiple regression analysis was conducted for the NV mode.

$$
\begin{gathered}
T_{\mathrm{c} i}=0.535 T_{i}-0.032 R H_{i}+14.1\left(n=1860, R^{2}=0.32, p<0.001\right) \\
T_{\mathrm{c} i}=0.650 T_{i}-0.128 A H_{i}+10.8\left(n=1860, R^{2}=0.32, p<0.001\right) \\
T_{\mathrm{c} i}=0.777 T_{i}-1.307 S M+7.2\left(n=1860, R^{2}=0.56, p<0.001\right)
\end{gathered}
$$

where $T_{\mathrm{c} i}$ : Comfort indoor temperature $\left({ }^{\circ} \mathrm{C}\right) ; R H_{i}$ : Indoor relative humidity $(\%) ; A H_{i}$ : Indoor absolute humidity (g/kg'); SM: Skin moisture sensation.

As shown in the equations, the relative humidity and absolute humidity have no important effect on the comfort temperature. However, Nicol [12] found that in a humid climate or in conditions when the relative humidity is high people may require temperatures that are about $1{ }^{\circ} \mathrm{C}$ lower to remain comfortable. As for the skin moisture, it has significantly affected the comfort temperature (Figure 7). Nicol [20] found that when indoor air temperature is $31-40{ }^{\circ} \mathrm{C}$, the increased wind velocity reduced the skin moisture. 
The results showed that the evaporation of the skin moisture is important to increase the comfort temperature in Japan's hot and humid season.

Table 9. Correlation coefficient in NV mode.

\begin{tabular}{ccccccc}
\hline Items & $\boldsymbol{T}_{\mathrm{c} i}: \boldsymbol{R H}_{\boldsymbol{i}}$ & $\boldsymbol{T}_{\mathrm{cg}}: \boldsymbol{R H}_{\boldsymbol{i}}$ & $\boldsymbol{T}_{\mathrm{c} \boldsymbol{i}}: \boldsymbol{A H}_{\boldsymbol{i}}$ & $\boldsymbol{T}_{\mathrm{cg}}: \boldsymbol{A} \boldsymbol{H}_{\boldsymbol{i}}$ & $\boldsymbol{T}_{\mathrm{c} \boldsymbol{i}}: \boldsymbol{S M}$ & $\boldsymbol{T}_{\mathrm{cg}}: \boldsymbol{S M}$ \\
\hline$r$ & -0.37 & -0.34 & -0.03 & -0.01 & -0.35 & -0.34 \\
$p$ & $<0.001$ & $<0.001$ & 0.135 & 0.784 & $<0.001$ & $<0.001$ \\
$N$ & 1860 & 1860 & 1860 & 1860 & 1860 & 1915 \\
\hline
\end{tabular}

$r$ : Correlation coefficient; $\mathrm{p}$ : Significant level; $N$ : Number of sample; $T_{\mathrm{c} i}$ : Comfort indoor temperature $\left({ }^{\circ} \mathrm{C}\right)$; $T_{\text {cg: }}$ : Comfort globe temperature $\left({ }^{\circ} \mathrm{C}\right) ; R H_{i}$ : Indoor relative humidity (\%); $A H_{i}$ : Indoor absolute humidity $\left(\mathrm{g} / \mathrm{kg}^{\prime}\right) ; S M$ : Skin moisture sensation.

Figure 7. Relation between the comfort air temperature and the skin moisture sensation.

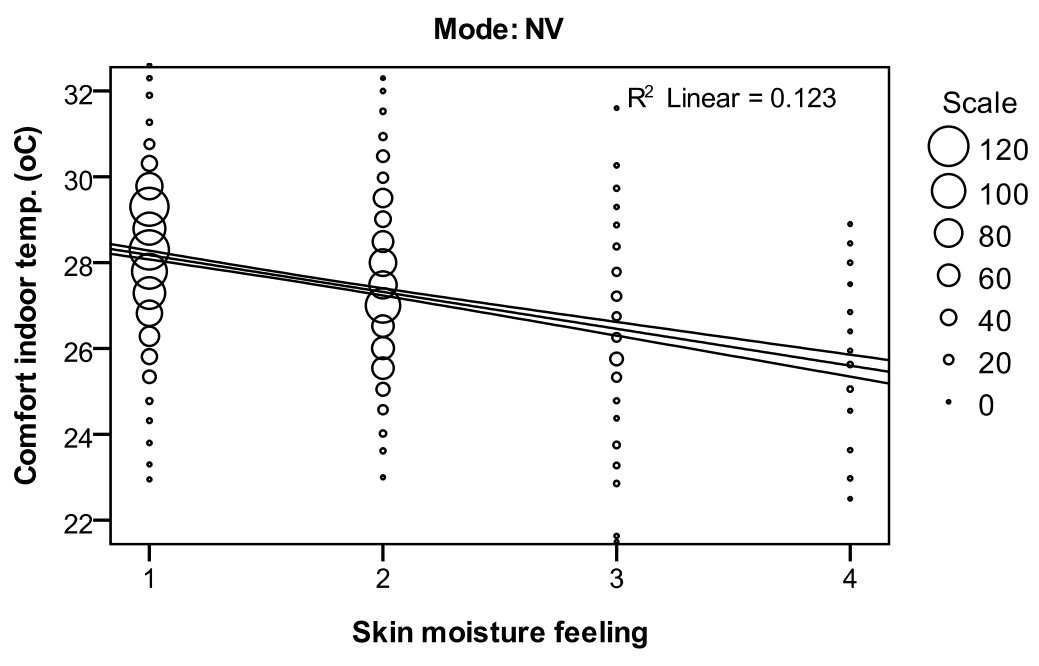

\subsection{A Comparison with the Adaptive Model}

It is well known that people adapt to the outdoor temperature, and thus comfort temperature has seasonal and regional differences [14]. To predict such comfort temperature, the CEN and CIBSE proposed the adaptive model for office buildings. We wished to compare our results with these adaptive models.

The running mean outdoor temperature $\left(T_{\mathrm{rm}}\right)$ is used in the adaptive model which is the exponentially weighted daily mean outdoor temperature. It is calculated using the following equation $[11,17,21,22]$.

$$
T_{\mathrm{rm}}=\alpha T_{\mathrm{rm}-1}+(1-\alpha) T_{\mathrm{od}-1}
$$

where $T_{\mathrm{rm}-1}$ is the running mean outdoor temperature for the previous day $\left({ }^{\circ} \mathrm{C}\right), T_{\mathrm{od}-1}$ is the daily mean outdoor temperature for the previous day $\left({ }^{\circ} \mathrm{C}\right.$ ). So, if the running mean has been calculated (or assumed) for one day, then it can be readily calculated for the next day, and so on. $\alpha$ is a constant between the 0 and 1 which defines the speed at which the running mean responds to the outdoor air temperature. In this research $\alpha$ is assumed to be 0.8 .

Figure 8 shows the relation between the comfort temperature and the running mean outdoor temperature. The six parallel lines in Figure 8a show the acceptable zone of the adaptive model of CEN standard [11]. The two parallel lines in Figure 8b show upper and lower margins of the comfort temperature [22]. The Japanese guide line is also shown in the figure. 
Generally the comfort temperature of NV mode is within the acceptable zone of the adaptive model. As for the AC mode, the comfort temperature is higher than the CIBSE guide [22]. The results showed that the residents are living by adapting to the higher indoor air temperature of the houses.

Figure 8. Comparison with the adaptive model: (a) NV mode (CEN standard); (b) AC mode (CIBSE guide).
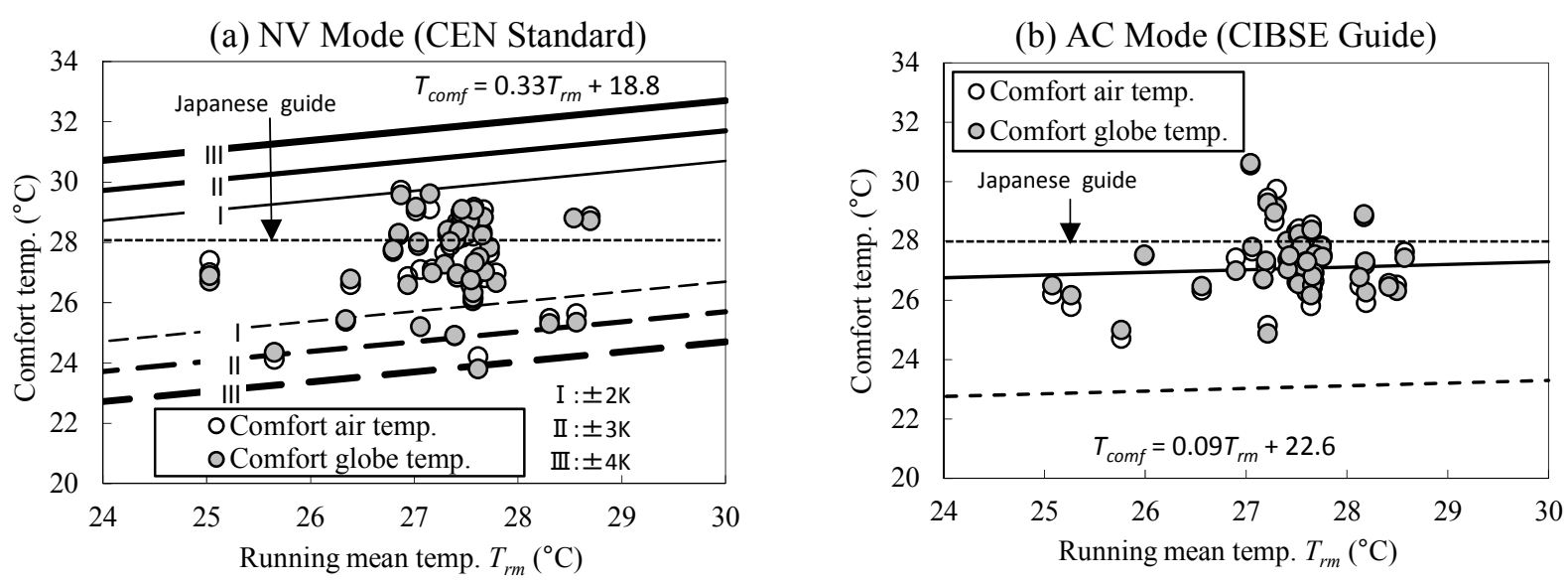

\subsection{Occupant Behavior}

As we have shown in the previous sections, the residents questioned are living by adapting to higher indoor air temperature of the houses. Residents might be regulating the thermal environments by using various adaptations: behavioral, physiological and psychological [23]. This section focuses on the behavioral adaptation. Nicol and Humphreys [24] made use of logistic regression analysis to predict occupant control behavior in naturally ventilated buildings. We have also adopted the logistic regression method to predict the window opening and fan use in the living room. The relationship between the probability of windows open or fan use $(p)$ and the indoor or outdoor temperature $(T)$ is of the form:

$$
\begin{gathered}
\operatorname{logit}(p)=\log \{p /(1-p)\}=b T+c \\
p=\exp ^{(b T+c)} /\left\{1+\exp ^{(b T+c)}\right\}
\end{gathered}
$$

where exp (exponential function) is the base of natural logarithm, $b$ is the regression coefficient for $T$, and $c$ is the constant in the regression equation.

The following regression equations were obtained in between the window opening or fan use and temperatures for NV mode.

Window opening:

$$
\begin{aligned}
& \operatorname{logit}(p)=0.239 T_{i}-5.3\left(n=1860, R^{2}=0.02, p<0.001\right) \\
& \operatorname{logit}(p)=0.250 T_{\mathrm{g}}-5.6\left(n=1915, R^{2}=0.02, p<0.001\right) \\
& \operatorname{logit}(p)=0.109 T_{\mathrm{o}}-1.4\left(n=1915, R^{2}=0.01, p<0.001\right)
\end{aligned}
$$

Fan use:

$$
\operatorname{logit}(p)=0.309 T_{i}-9.1\left(n=1860, R^{2}=0.05, p<0.001\right)
$$




$$
\begin{aligned}
& \operatorname{logit}(p)=0.289 T_{\mathrm{g}}-8.6\left(n=1915, R^{2}=0.05, p<0.001\right) \\
& \operatorname{logit}(p)=0.206 T_{\mathrm{o}}-5.9\left(n=1915, R^{2}=0.05, p<0.001\right)
\end{aligned}
$$

where $T_{i}$ is indoor air temperature $\left({ }^{\circ} \mathrm{C}\right), T_{\mathrm{g}}$ is indoor globe temperature $\left({ }^{\circ} \mathrm{C}\right), T_{\mathrm{o}}$ is outdoor air temperature $\left({ }^{\circ} \mathrm{C}\right)$ and $R^{2}$ is Cox and Snell $R^{2}$.

These equations are shown in Figure 9. The predicted window opening or fan use is well matched with the measured values. The proportion of window opening or fan use is increased when temperature rises. The window opening behavior is similar to the previous research [5,18].

The regression coefficient for indoor air temperature or globe temperature is higher than the outdoor air temperature. It seems that the occupants respond more closely to the indoor temperatures than outdoor air temperature while operating the windows and fans.

Window opening and fan use might be important to increase the air movement and lower the indoor air temperature. Window opening is effective at increasing the indoor comfort temperature $[5,25]$. Theoretically, if wind velocity is $1 \mathrm{~m} / \mathrm{s}$, the indoor comfort temperature can be increased by some 3 or $4{ }^{\circ} \mathrm{C}[12,26,27]$. Nicol [12] found that the presence of air movement can be equivalent to a reduction in indoor temperature of as much as $4{ }^{\circ} \mathrm{C}$. When outdoor running mean temperature is $30{ }^{\circ} \mathrm{C}$, the indoor comfort temperature when the fan is on is $31{ }^{\circ} \mathrm{C}$ which is $2.2{ }^{\circ} \mathrm{C}$ higher than when the fan is off $[18,27]$.

Thus, the results showed that residents undertake behavioral adaptation to regulate their hot and humid thermal environment.

Figure 9. Relation between the use of controls and temperature: (a) Window opening; (b) Fan use. Measured values were grouped for every $1{ }^{\circ} \mathrm{C}$ for indoor or outdoor air temperature. The grouped data for samples less than 10 are not shown.

(a) Window opening

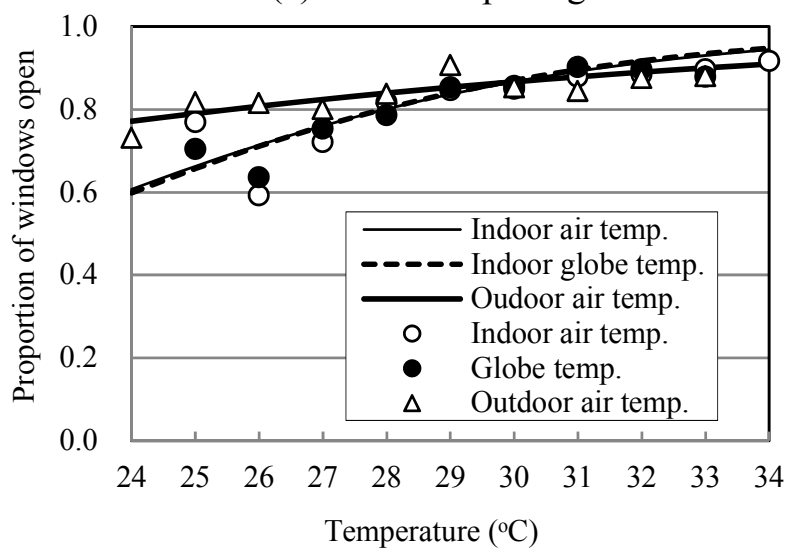

(b) Fan use

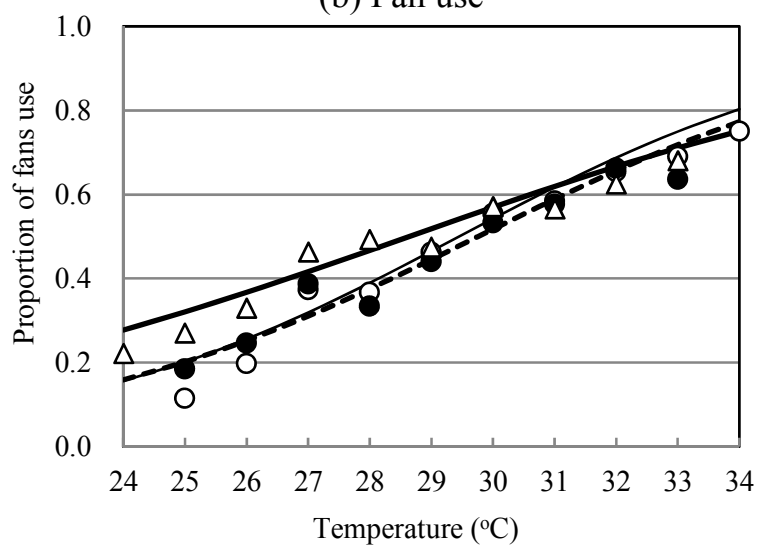

\section{Conclusions}

In order to clarify the comfort temperature and to investigate the behavioral adaptation in Japanese houses, we conducted a thermal comfort survey and occupant behavior survey in 30 living rooms for the hot and humid season in the Kanto region of Japan. Following are the results: 
(1) The proportion of people voting in the thermal comfort zone is $84 \%$ in NV mode, and thus the residents are highly adapted and satisfied with the thermal environment of their houses.

(2) The mean comfort temperature in naturally ventilated mode is $27.6{ }^{\circ} \mathrm{C}$ (standard deviation $=$ $1.8{ }^{\circ} \mathrm{C}$ ) in hot and humid season. The results showed that the comfort temperature of this study is within the acceptable zone of the adaptive model.

(3) The comfort temperature is related with skin moisture sensation, and thus the evaporation of the skin moisture is important to increase the comfort temperature in hot and humid season.

(4) The residents adapt to hot and humid environments by increasing the air movement usage through the behavioral adaptive actions such as opening the windows and using fans.

\section{Acknowledgments}

This research was supported by Grant-in-Aid for Scientific Research (C) Number 24560726 and (B) Number 25289200. I would like to thank to Madhavi Indraganti for reviewing the paper. I would like to give especial thanks to Michael Humphreys and Fergus Nicol of Oxford Brookes University for their research guidance.

\section{Conflicts of Interest}

The author declares no conflict of interest.

\section{References}

1. Nakaya, T.; Matsubara, N.; Kurazumi, Y. A field study of thermal environment and thermal comfort in Kansai region, Japan: Neutral temperature and acceptable range in summer. J. Environ. Eng. AIJ 2005, 597, 51-56.

2. Yoshimura, S.; Rijal, H.B.; Kikuchi, S. Research on the comfort temperature and the adaptive model of houses. AIJ Kanto Chapter Archit. Res. Meet. 2012, 82, 113-116.

3. Rijal, H.B.; Yoshimura, S. Investigation of Comfort Temperature in Naturally Ventilated and Air Condition Mode in Japanese Houses. In Proceedings of the 4th International Conference on Human-Environment System, Sapporo, Japan, 3-6 October 2011; pp. 259-264.

4. Katsuno, J.; Rijal, H.B.; Kikuchi, S. Investigation of the Comfort Temperature and Adaptive Model in Japanese Houses in Summer. In Proceedings of 7th Conference: The Changing Context of Comfort in an Unpredictable World, Windsor, UK, 12-15 April 2012.

5. Rijal, H.B.; Honjo, M.; Kobayashi, R.; Nakaya, T. Investigation of comfort temperature, adaptive model and the window opening behaviour in Japanese houses. Archit. Sci. Rev. 2013, 56, 54-69.

6. Rijal, H.B.; Yoshida, H.; Umemiya, N. Seasonal and regional differences in neutral temperatures in Nepalese traditional vernacular houses. Build. Environ. 2010, 45, 2743-2753.

7. Nicol, F.; Jamy, G.N.; Sykes, O.; Humphreys, M.; Roaf, S.; Hancock, M. A Survey of Thermal Comfort in Pakistan toward New Indoor Temperature Standards; Oxford Brookes University: Oxford, UK, 1994.

8. Nicol, F.; Roaf, S. Pioneering new indoor temperature standards: The Pakistan project. Energy Build. 1996, 23, 169-174. 
9. Rijal, H.B.; Stevenson, F. Thermal Comfort in UK Housing to Avoid Overheating: Lessons from a "Zero Carbon" Case Study. In Proceedings of the Conference: Adapting to change: New thinking on comfort, Windsor, UK, 9-11 April 2010.

10. AHRAE Standard 55. Thermal Environment Conditions for Human Occupancy; American Society of Heating Refrigeration and Air-Conditioning Engineers: Atlanta, GA, USA, 2004.

11. Comité Européen de Normalisation (CEN). Indoor Environmental Input Parameters for Design and Assessment of Energy Performance of Buildings Addressing Indoor Air Quality, Thermal Environment, Lighting and Acoustics; EN 15251; CEN: Brussels, Belgium, 2007.

12. Nicol, F. Adaptive thermal comfort standards in the hot-humid tropics. Energy Build. 2004, 36, 628-637.

13. McIntyre, D.A. Indoor Climate; Applied Science Publishers, Ltd.: London, UK, 1980.

14. Humphreys, M.A. Outdoor temperatures and comfort indoors. Build. Res. Pract. 1978, 6, 92-105.

15. Finney, D.J. Probit Analysis; Cambridge University Press: Cambridge, UK, 1971.

16. Griffiths, I.D. Thermal Comfort in Buildings with Passive Solar Features: Field Studies, Report to the Commission of the European Communities; EN3S-090 UK: University of Surrey Guildford: Surrey, UK, 1990.

17. Nicol, F.; Humphreys, M.; Roaf, S. Adaptive Thermal Comfort: Principles and Practice; Earthscan: London, UK, 2012.

18. Rijal, H.B.; Tuohy, P.; Humphreys, M.A.; Nicol, J.F.; Samuel, A.; Raja, I.A.; Clarke, J. Development of adaptive algorithms for the operation of windows, fans and doors to predict thermal comfort and energy use in Pakistani buildings. ASHRAE Trans. 2008, 114, 555-573.

19. Humphreys, M.A.; Rijal, H.B.; Nicol, J.F. Updating the adaptive relation between climate and comfort indoors; new insights and an extended database. Build. Environ. 2013, 63, 40-55.

20. Nicol, J.F. An analysis of some observations of thermal comfort in Roorkee, India and Baghdad, Iraq. Ann. Human Biol. 1974, 1, 411-426.

21. McCartney, K.J.; Nicol, J.F. Developing an adaptive control algorithm for Europe, Energy and Buildings. Energy Build. 2002, 34, 623-635.

22. Humphreys, M.A.; Nicol, J.F. Chapter 1, Environmental Criteria for Design. Environmental Design: CIBSE Guide A; CIBSE: London, UK, 2006.

23. Brager, G.; de Dear, R. Thermal adaptation in the built environment: A literature review. Energy Build. 1998, 27, 83-96.

24. Nicol, J.F.; Humphreys, M.A. A stochastic approach to thermal comfort-Occupant behavior and energy use in buildings. ASHRAE Trans. 2004, 110, 554-568.

25. Brager, G.S.; Paliaga, G.; de Dear, R. Operable windows, personal control, and occupant comfort. ASHRAE Transac. 2004, 110, 17-33.

26. Humphreys, M.A. A simple theoretical derivation of thermal comfort conditions. J. Instit. Heat. Vent. Eng. 1970, 38, 95-98. 
27. Rijal, H.B. Chapter 3: Thermal Adaptation Outdoors and the Effect of Wind on Thermal Comfort. In Ventilating Cities Air-flow-Criteria for Healthy and Comfortable Urban Living; Kato, S., Hiyama, K., Eds.; Springer: London, UK, 2012; pp. 33-58.

(C) 2014 by the authors; licensee MDPI, Basel, Switzerland. This article is an open access article distributed under the terms and conditions of the Creative Commons Attribution license (http://creativecommons.org/licenses/by/3.0/). 